\title{
WEE1 inhibition sensitizes osteosarcoma to radiotherapy
}

\author{
Jantine PosthumaDeBoer ${ }^{1}$, Thomas Würdinger ${ }^{2,3}$, Harm CA Graat ${ }^{1}$, Victor W van Beusechem ${ }^{4}$, Marco N Helder ${ }^{1,5}$, \\ Barend J van Royen ${ }^{1,5}$ and Gertjan JL Kaspers ${ }^{6^{*}}$
}

\begin{abstract}
Background: The use of radiotherapy in osteosarcoma (OS) is controversial due to its radioresistance. OS patients currently treated with radiotherapy generally are inoperable, have painful skeletal metastases, refuse surgery or have undergone an intralesional resection of the primary tumor. After irradiation-induced DNA damage, OS cells sustain a prolonged $G_{2}$ cell cycle checkpoint arrest allowing DNA repair and evasion of cell death. Inhibition of WEE1 kinase leads to abrogation of the $G_{2}$ arrest and could sensitize OS cells to irradiation induced cell death.
\end{abstract}

Methods: WEE1 expression in OS was investigated by gene-expression data analysis and immunohistochemistry of tumor samples. WEE1 expression in OS cell lines and human osteoblasts was investigated by Western blot. The effect of WEE1 inhibition on the radiosensitivity of OS cells was assessed by cell viability and caspase activation analyses after combination treatment. The presence of DNA damage was visualized using immunofluorescence microscopy. Cell cycle effects were investigated by flow cytometry and WEE1 kinase regulation was analyzed by Western blot.

Results: WEE1 expression is found in the majority of tested OS tissue samples. Small molecule drug PD0166285 inhibits WEE1 kinase activity. In the presence of WEE1-inhibitor, irradiated cells fail to repair their damaged DNA, and show higher levels of caspase activation. The inhibition of WEE1 effectively abrogates the irradiation-induced $\mathrm{G}_{2}$ arrest in OS cells, forcing the cells into premature, catastrophic mitosis, thus enhancing cell death after irradiation treatment.

Conclusion: We show that PD0166285, a small molecule WEE1 kinase inhibitor, can abrogate the $G_{2}$ checkpoint in OS cells, pushing them into mitotic catastrophe and thus sensitizing OS cells to irradiation-induced cell death. This suggests that WEE1 inhibition may be a promising strategy to enhance the radiotherapy effect in patients with OS.

\section{Background}

Osteosarcoma (OS) is the most common primary malignant bone tumor in children and adolescents. The gold standard for treatment of OS consists of multi-agent neoadjuvant chemotherapy, radical excision of the tumor and adjuvant chemotherapy [1-3]. With this treatment regimen, 5-year survival rates of approximately $65 \%$ are obtained in localized disease. In patients with axial and/or inoperable OS, local control is difficult to achieve and there is a high risk of relapse and/or metastasis. The prognosis for these patients is worse with a 5-year survival of around $25 \%$ [4-7]. Clearly,

\footnotetext{
* Correspondence: gjl.kaspers@vumc.nl

${ }^{6}$ Paediatric Oncology/Haematology, VU University Medical Center, PO box

7057, 1007 MB Amsterdam, the Netherlands

Full list of author information is available at the end of the article
}

alternative treatment options for OS are warranted for patients in whom local control can be scarcely achieved and therefore have a high risk of recurrence. Radiotherapy as a treatment modality for cancer has evolved over the past decades, but its use in OS treatment is controversial because OS is considered to be a relatively radioresistant tumor $[2,3,5,7]$. At present, radiotherapy is applied only in a select group of patients with OS, namely those who suffer from inoperable (advanced extremity, axial or head-and-neck) OS, patients with painful bone metastases and patients who refuse surgery. Radiotherapy can give local control in OS when applied as an adjuvant therapy in patients who have undergone an intralesional resection of the primary tumor with subsequent irradiation of the surgical margins [1-3,5,8-11]. Technical progression in the field of
Ciomed Central 
radiotherapy has facilitated a more precise localised delivery of radiation and thus warranted dose-intensification at the site of the tumor. This is of value since the high irradiation doses needed for tumor control are difficult to achieve in patients with tumors that lie in the proximity of delicate structures, as is often the case in axial OS. Regularly, adverse side effects limit the dose that can be applied. Although still considered an advanced technique, the use of proton radiotherapy can be even more exactly localized to deliver a higher irradiation dose in the tumor while sparing adjacent healthy tissues. The toxicity and efficacy of this method in bone sarcomas is studied in clinical trial setting $[11,12]$. Furthermore, the use of radiosensitizing drugs has further improved the anti-tumor efficacy of radiotherapy $[3,5,8,13,14]$. Conventional chemotherapy has been shown to enhance the effect of radiotherapy in OS. Gemcitabine (with or without Docetaxel) and Ifosfamide have been shown to be potent radiosensitizers $[3,15]$. Also, the use of 153-Samarium can enhance the antitumor effect of external beam radiotherapy in axial OS $[3,5,9,13]$. Thus, chemotherapeutic agents may be used as radiosensitizers in OS patients. Moreover, small molecule inhibitor drugs may serve as additional radiosensitizers $[13,16]$.

Radiotherapy, like many other cancer treatments, induces damage to the DNA. Prolonged activation of cell cycle checkpoints (arrest) is one effective method exploited by cancer cells to repair DNA and thus evade apoptosis after DNA-damaging treatments [16-20]. When cells progress through the cell cycle despite the presence of DNA damage, as a result, they undergo a mitosis specific cell death programme called mitotic catastrophe [16-18,20-23]. Cancer cells often lack a functional $\mathrm{G}_{0} / 1$ cell cycle checkpoint and therefore rely mainly on the $G_{2}$ cell cycle arrest to gain time for DNA repair [20,23-27]. Therefore, one strategy to sensitize OS cells to DNA damaging treatments is to exploit their vulnerability in defective cell cycle regulation and prevent them from repairing the damaged DNA during $G_{2}$ arrest. WEE1 kinase plays a dominant role in the sensitivity of cancer cells to DNA damage by inhibitory phosphorylation of Cyclin-Dependent-Kinase 1 (CDC2), thereby preventing mitotic entry, which is illustrated in Figure 1A,[16-20,27-33]. It has been shown that PD0166285, a small molecule WEE1 kinase inhibitor, can abrogate the $G_{2}$ checkpoint in cancer cells, forcing DNA-damaged cells into premature mitotic entry thus inducing mitotic catastrophe and sensitizing the cells to apoptosis. The anti-tumor activity of WEE1 inhibition in combination with DNA damaging treatments has been demonstrated in vitro as well as in vivo models for different malignancies $[16,21,28,29]$. These promising preclinical results have led to the testing of a small molecule WEE1-inhibitor in a phase I clinical trial [27]. The aim of our study is to investigate if irradiation in combination with WEE1 inhibition could be used as a new therapeutic strategy to improve local control in the treatment of OS.

\section{Methods}

\section{Cell culture, irradiation and compounds}

Human osteosarcoma cell lines MG-63, U2OS and SaOS-2 were kindly provided by Dr. C. Löwik (Leiden University Medical Center, Leiden, the Netherlands), Dr. S. Lens (Dutch Cancer Institute, Amsterdam, the Netherlands) and Dr. F. van Valen (Westfalische WilhelmsUniversität, Münster, Germany) respectively. Human primary (short-term culture) osteoblasts (ORT-1, Hum31 and Hum54) were obtained from healthy patients undergoing total knee replacement after informed consent. Cells were cultured in D-MEM (Gibco, Invitrogen) supplemented with 10\% fetal calf serum (FCS) and $1 \mathrm{mg} / \mathrm{mL}$ Penicillin-Streptomycin (Gibco) at $37^{\circ} \mathrm{C}$ and $5 \% \mathrm{CO} 2$ in a humidified incubator.

Cells were irradiated in a Gammacell ${ }^{\circledR} 220$ Research Irradiator (MDS Nordion) at doses varying from 2 to 10 Gray (Gy). The WEE1-inhibitor PD0166285 (Pfizer, Ann Arbor, MI, USA) was diluted in PBS to the desired concentration of $0.5 \mu \mathrm{M}$.

\section{Immunohistochemistry}

Paraffin embedded tissue samples of primary OS and OS lung metastases, obtained from excision specimens from our institute, were deparafinized and rehydrated. Endogenous peroxidase was inhibited by 30 minutes incubation of the sections in $0.3 \% \mathrm{H}_{2} \mathrm{O}_{2}$, diluted in methanol. Antigens were retrieved by boiling in citrate buffer $(\mathrm{pH}$ 6) for 10 minutes, followed by successive rinses in phosphate-buffered saline (PBS) containing $0.5 \%$ Triton and then in PBS only. Slides were incubated for 10 minutes in $0.1 \mathrm{M}$ glycine (diluted in PBS) and rinsed in PBS. Slides were incubated with mouse-anti-WEE1 (SantaCruz) $\mathrm{O} / \mathrm{N}$ at $4{ }^{\circ} \mathrm{C}$. Visualisation was performed using the Power Vision ${ }^{+}$Poly-HRP IHC Kit (Immunologic) and tissue staining was performed with DAB chromogen solution. Slides were counterstained with hematoxylin, dehydrated and mounted. Placenta tissue served as positive control, prostate tissue served as negative control (not shown). Images were acquired at 20x objective.

\section{Western Blot}

Basic expression levels of WEE1 and phosphorylated CDC2 in human OS cell lines and human primary osteoblasts were assessed by Western blot. Cells were lysed in phospho-lysis buffer containing Protease and Phosphatase Inhibitor Cocktails (Sigma). Proteins were quantified with the BCA protein Assay Kit (Pierce). A 


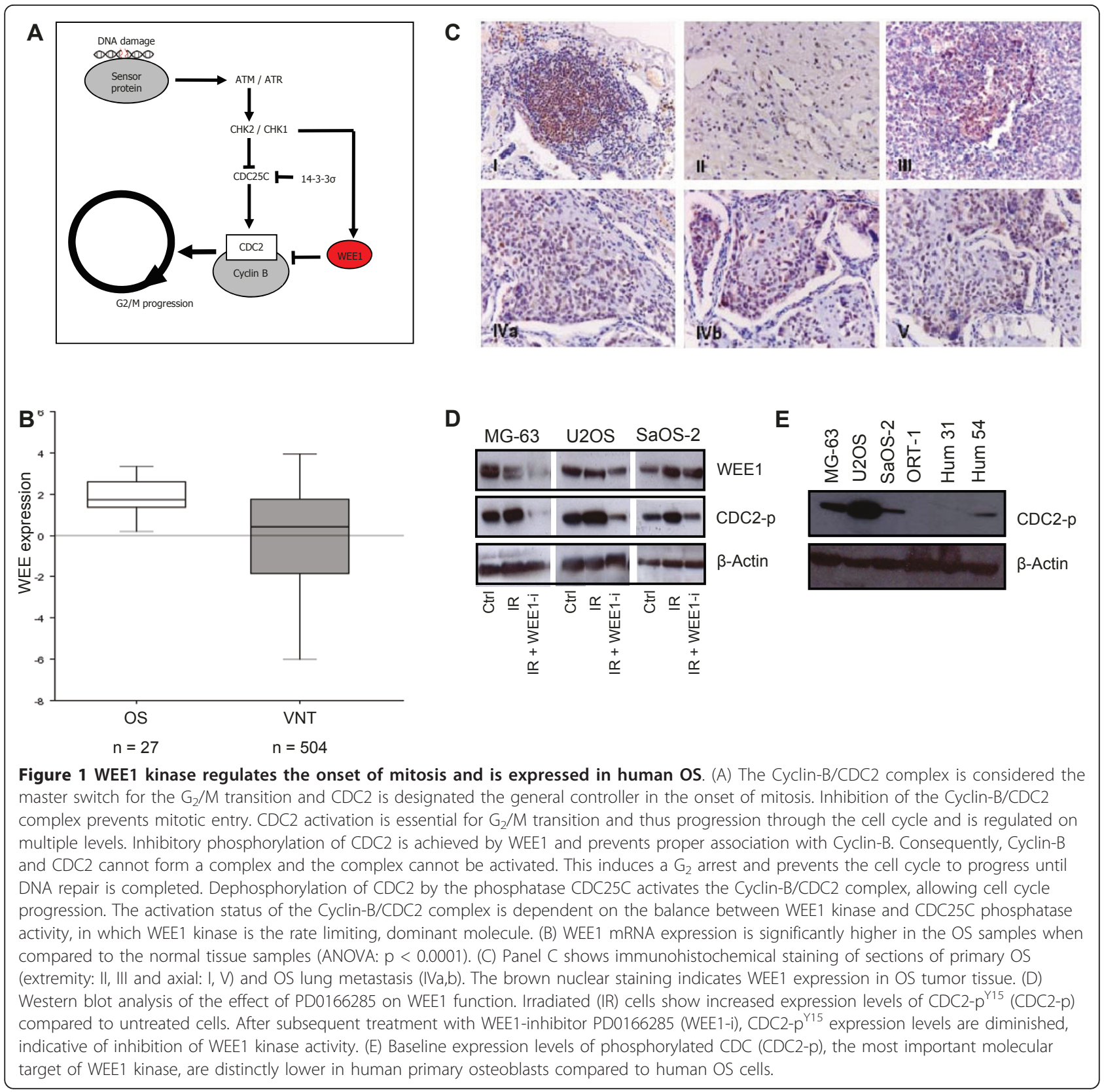

total of $40 \mu \mathrm{g}$ protein was separated on a SDS-PAGE gel and transferred to a PVDF membrane, followed by incubation with the primary antibodies: mouse anti-WEE1 (SantaCruz), mouse anti- $\beta$-actin (SantaCruz) and rabbit anti-CDC2- $\mathrm{p}^{\mathrm{Y} 15}$ (Abcam) and subsequently incubated with secondary goat-anti-mouse and goat-anti-rabbit immunoglobulins (DAKO). Protein detection and visualization was performed using $\mathrm{ECL}^{+}$Western Blotting Detection Reagents (Pierce).

Inhibition of WEE1 kinase activity and concomitant phosphorylation of $\mathrm{CDC} 2$ by the WEE1-inhibitor PD0166285 was also analyzed by Western blot analysis.
Cells were plated and irradiated at a dose of 4 Gy in the presence or absence of $0.5 \mu \mathrm{M}$ PD0166285. After $4 \mathrm{~h}$ treatment with $0.5 \mu \mathrm{M}$ PD0166285, cells were lysed in phospho-lysis buffer, followed by Western blot analysis as described above.

\section{Cell Viability and apoptosis assay}

For cell viability analysis, OS cells and primary osteoblasts were plated in 96-well format and irradiated at doses of 2, 3, 4, 6, 8 and 10 Gy. Cells were incubated with $0.5 \mu \mathrm{M}$ PD0166285 or PBS directly post-irradiation. At 4 days (OS) and 9 days (osteoblasts) after treatment 
cell viability was assessed using the CellTiter-Blue Cell Viability Assay (Promega) according to the manufacturer's instructions.

To analyse apoptosis, OS cells were plated in white opaque 96-well plates and treated with 4 Gy irradiation or with combination treatment of $4 \mathrm{~Gy}$ and $0.5 \mu \mathrm{M}$ PD0166285. At $6 \mathrm{~h}$ and 24h post-irradiation, caspase activity was measured using the Caspase-Glo 3/7 assay (Promega) according to the manufacturer's instructions.

Fluorescence and luminescence read-out was performed using a Tecan Infinite F200 Microplate Reader (Tecan Trading AG, Switzerland). Results were analysed using GraphPad Prism ${ }^{\circledR}$ Version 5.01 (GraphPad Software, Inc. San Diego, CA, USA).

\section{Flow cytometry}

Cell cycle distribution and the percentage of mitotic cells were analysed using flow cytometry. Cells were plated and treated with 4 Gy irradiation, $0.5 \mu \mathrm{M}$ PD0166285 or combination treatment. At $20 \mathrm{~h}$ after treatment cells were trypsinized, washed in PBS containing 1\% FCS and fixed in 70\% ice-cold ethanol for $24 \mathrm{~h}$. After fixation, cells were washed with PBS containing $1 \%$ FCS and incubated with rat-anti-phospho-histone H3 (PHH3) antibody (BD Pharmingen) in PBS containing $1 \%$ BSA for $2 \mathrm{~h}$ at room temperature, followed by secondary antibody incubation with rabbit-anti-rat/FITC immunoglobulins (DAKO) in PBS containing 1\% BSA for 30 minutes at room temperature in the dark. Cells were washed once and DNA was stained with $50 \mu \mathrm{g} / \mathrm{mL}$ propidium iodide (PI) solution in the presence of 250 $\mu \mathrm{g} / \mathrm{mL}$ RNAseA (Sigma). The DNA content and the percentage of $\mathrm{PHH} 3$ positive cells were measured using a FacsCalibur Flow Cytometer and the Cell Quest Pro programme (Becton Dickinson) and results were subsequently analysed using ModFitLT software (Verity Software House, Topsham, ME, USA).

\section{Immunofluorescent Staining}

OS cells were seeded on glass coverslips in 24-well plates and treated with 4 Gy irradiation or with combination treatment of $4 \mathrm{~Gy}$ and $0.5 \mu \mathrm{M}$ PD0166285. At 1 $\mathrm{h}$ and $24 \mathrm{~h}$ post-irradiation cells were fixed in $2 \%$ paraformaldehyde. Prior to staining, the cells were rinsed in PBS and permeabilized in PBS containing $0.1 \%$ Trition X-100 for 30 minutes at room temperature and blocked in PBS containing 5\% FCS. Slips were incubated with mouse-anti- $\gamma$-histone-H2AX (Millipore) in PBS containing $5 \% \mathrm{FCS} \mathrm{O} / \mathrm{N}$ at $4{ }^{\circ} \mathrm{C}$, followed by secondary antibody incubation rabbit-anti-mouse/FITC immunoglobulins (DAKO) in PBS containing 5\% FCS for 30 minutes at room temperature in the dark. Slips were rinsed in PBS thrice and nuclei were stained with DAPI (1:10 000) in PBS at room temperature in the dark, followed by successive rinses in PBS and sterile water. The slips were then mounted on glass slides, fixed with Mowiol and analyzed with a Carl Zeiss Axioskop 20 microscope at $100 \mathrm{x}$ objective.

\section{Results}

To investigate whether WEE1 could be a suitable drug target in human OS we first explored its expression levels. From publicly available gene expression data in the GEO Expression Omnibus (http://www.ncbi.nlm.nih. gov/geo: GSE14827), we analyzed WEE1 expression in 27 OS samples and 504 various normal tissue samples using the software programme R2 [34]. We determined that WEE1 kinase is overexpressed in OS compared to various normal tissues, as shown in Figure 1B. When comparing the mRNA expression level of WEE1 in OS samples to the normal various tissue samples, one-way analysis-of-variance (ANOVA) shows that WEE1 expression is significantly higher in the OS samples ( $\mathrm{p}<$ 0.0001 ). In addition, we determined WEE1 protein expression in human OS tissue sections by immunohistochemical staining. Five out of 6 tested tumors had positive nuclear WEE1 staining (Figure 1C). The nuclear localization of the protein is in concordance with its role in cell cycle regulation. These data indicate that WEE1 is indeed expressed by OS and could thus serve as a potential drug target.

Next, we assessed whether PD0166285 can inhibit WEE1 kinase function by determining phosphorylation of its target CDC2 (resulting in CDC2-p ${ }^{\text {Y15}}$ ) using Western blot analysis. Irradiated cells showed a moderate increase in WEE1 expression and a more profound increase in expression of CDC2 - $\mathrm{p}^{\mathrm{Y} 15}$ compared to untreated cells (Figure 1D). This supports the notion that WEE1 kinase plays a role in the response to DNA damage by phosphorylation of CDC2. Subsequent treatment with PD0166285 diminished the expression of CDC2 $-\mathrm{p}^{\mathrm{Y} 15}$ after irradiation. This shows that PD0166285 effectively inhibits WEE1 activity and thus reduces the inhibitory phosphorylation of $\mathrm{CDC} 2$ in $\mathrm{OS}$ cells.

To analyse how baseline WEE1 and CDC2- $\mathrm{p}^{\mathrm{Y} 15}$ levels in OS cells compare to normal cells, we included a western blot analysis. Figure 1E shows that CDC2- $\mathrm{p}^{\mathrm{Y} 15}$ levels in human primary osteoblasts are negligible in comparison to the OS cell lines. WEE1 expression in the osteoblasts could not be visualised.

To investigate the effects of WEE1 inhibition on OS cell survival after $\gamma$-irradiation-induced DNA damage, we compared cell viability in irradiated cells in the presence or absence of the WEE1-inhibitor PD0166285. Figure 2A shows that WEE1 inhibition using PD0166285 at a non-toxic dose $(0.5 \mu \mathrm{M})$ increased cell death after 2 to 6 Gy $\gamma$-irradiation in the OS cell lines 


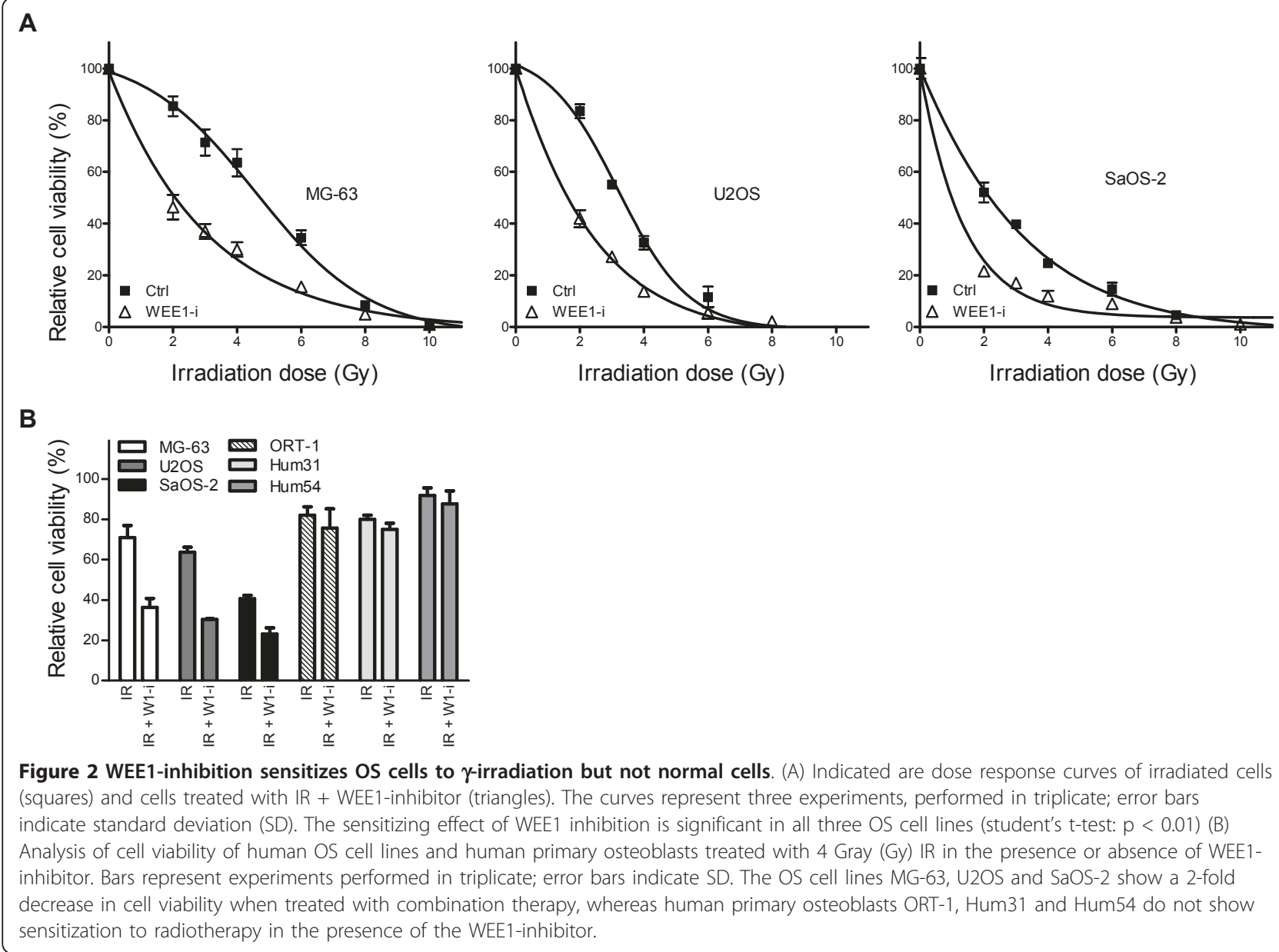

MG-63, U2OS and SaOS-2 ( $p<0.01)$, whereas treatment with $0.5 \mu \mathrm{M}$ WEE1-inhibitor alone showed no effect on cell viability (data not shown). To ascertain that WEE1 inhibition does not radiosensitize normal cells, we compared cell viability of human primary osteoblasts to osteosarcoma cell lines after 4 Gy irradiation, in the presence or absence of $0.5 \mu \mathrm{M}$ PD0166285. Figure 2B shows that in the osteosarcoma cell lines there is a clear sensitization to irradiation treatment, with approximately a 2 -fold reduction in cell viability after combination treatment. In contrast, in the human osteoblasts no such effects were seen. There is a minor decrease in cell viability due to the irradiation treatment, but WEE1 inhibition does not enhance cell death. The results were consistent for all three tested human primary osteoblasts. From this we conclude that OS cells are indeed sensitized to irradiation whereas normal cells are not.

To investigate if the sensitizing effect of WEE1 inhibition in OS could be explained by mitotic catastrophe, we looked into three aspects of this phenomenon. We performed FACS cell cycle analysis of cells treated with 4 Gy $\gamma$-irradiation, $0.5 \mu \mathrm{M}$ PD0166285, and combination treatment. Cells were stained with PI to analyse DNA content and with $\mathrm{PHH} 3$ to distinguish the fraction of mitotic cells from the cells in $G_{2} / M$ phase. Treatment with the WEE1-inhibitor alone did not alter the cell cycle distribution (Figure 3A). Irradiation of the cells resulted in arrest in the $G_{2} / M$ phase, indicated by an accumulation of cells with $4 \mathrm{~N}$ DNA content, but a stable percentage of mitotic cells. However, upon treatment of the irradiated cells with the WEE1-inhibitor, a clear abrogation of $G_{2}$ arrest was observed. Additionally, there was a 2 to 4 -fold increase in the percentage of mitotic cells.

To assess the extent of $\gamma$-irradiation-induced double strand DNA breaks (DSBs), we visualized the number of ionizing radiation induced foci (IRIF) with DSB marker $\gamma-\mathrm{H} 2 \mathrm{AX}$ at $1 \mathrm{~h}$ and $24 \mathrm{~h}$ after irradiation, in cells irradiated at a dose of $4 \mathrm{~Gy}$ in the presence or absence of $0.5 \mu \mathrm{M}$ PD0166285. Figure 3B shows that DNA damage is visible at $1 \mathrm{~h}$ after irradiation. In the irradiated cells, 


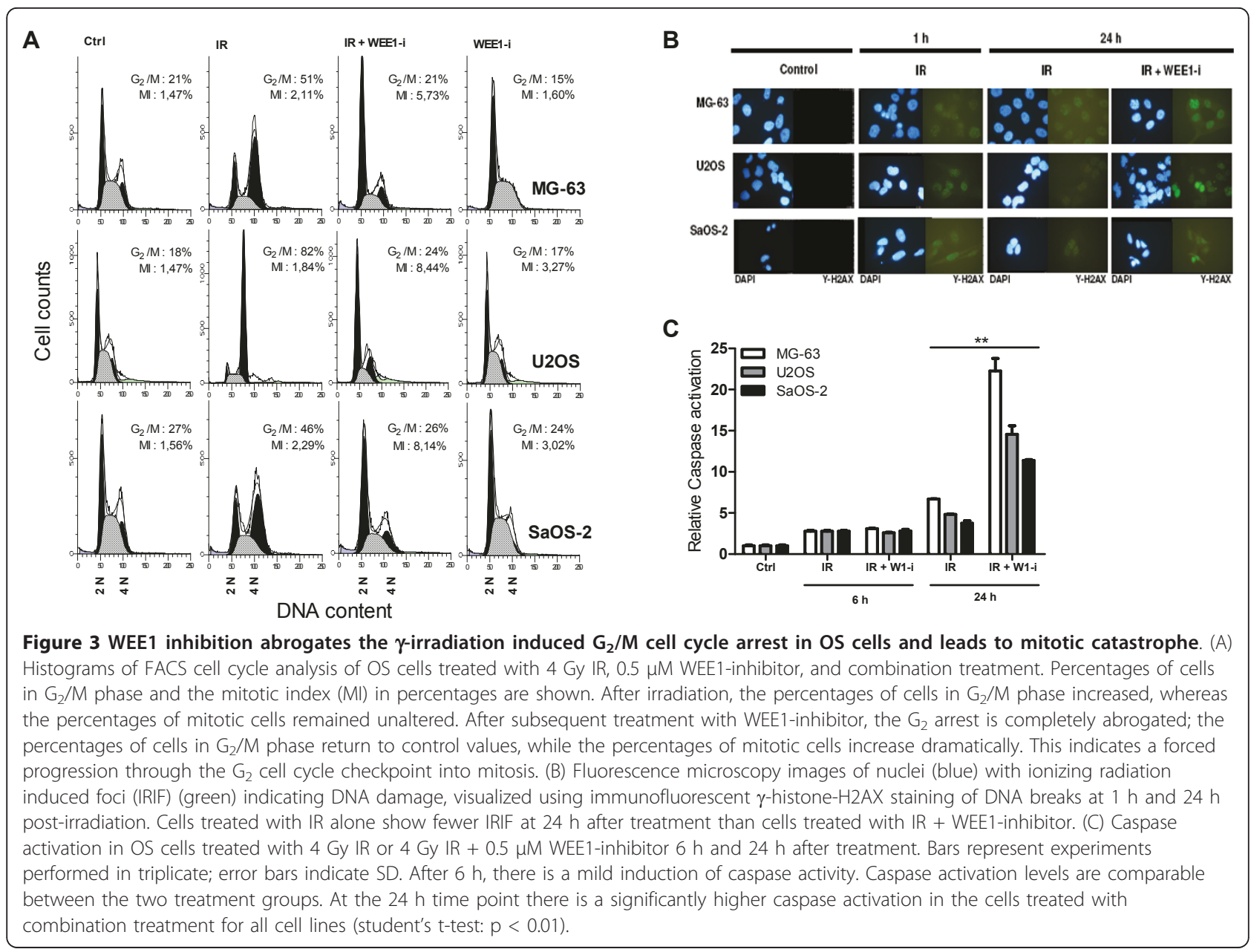

only a few residual foci are detectable after $24 \mathrm{~h}$ compared to the $1 \mathrm{~h}$ time point, indicating that DNA repair has occurred or is still ongoing. The shape of the nuclei is regular and there are no clear signs of apoptosis. In contrast, the cells treated with irradiation in combination with WEE1-inhibitor show extensive remaining DNA damage after $24 \mathrm{~h}$ with irregularity and fragmentation of nuclei indicative of nuclear envelope disassembly and apoptosis. From this we derive that in WEE1 inhibited cells DNA repair is not effectively realized.

To verify that cell death occurs as a result of apoptosis we analysed caspase activation in irradiated cells in the presence or absence of WEE1-inhibitor (Figure 3C). At $6 \mathrm{~h}$ post-irradiation there is a mild caspase activation in cells treated with irradiation alone or with combination treatment. However, at $24 \mathrm{~h}$ post-irradiation there is a distinct difference in caspase activation between irradiated cells (4 to 6-fold) and cells treated with the combination of irradiation and WEE1-inhibitor (11 to 22fold) ( $p<0.01$ for all three cell lines). Taken together, this implies that cells treated with the WEE1-inhibitor are forced to proceed through the $G_{2}$ cell cycle checkpoint into mitotic entry despite the presence of DNA damage and are therefore sensitized to $\gamma$-irradiation-induced apoptosis.

\section{Discussion}

In this work, we explore the possibility to use WEE1 inhibition as a new therapeutic strategy in OS. The use of WEE1-inhibitor PD0166285 to obtain radiosensitization in various malignancies has been reported previously $[18,21,28,29]$. The radiosensitization effect is described to be particularly effective in, if not limited to, p53 deficient malignancies $[18,28]$. Interestingly, we have found that our tested cell lines can all be sensitized to irradiation, regardless of their p53 status (wt in U2OS, mutated in MG-63 and null in SaOS-2). This, we ascribe to the idea that a defective $G_{1}$ checkpoint is not necessarily caused by p 53 mutations alone but rather a disruption in the p53 pathway, which can be caused by other aberrations within this pathway. We show that after irradiation, OS cells accumulate in a predominant $G_{2}$ arrest, the abrogation of which effectively leads to mitotic catastrophe. 
As was reported previously [21,27], our results confirm that normal cells remain unaffected by WEE1 inhibition after irradiation. We tested human primary osteoblasts for their response to irradiation in the presence or absence of WEE1-inhibitor. While there was a minor effect of irradiation on cell viability, no radiosensitization by PD0166285 was observed. This is likely explained by a functional $\mathrm{G}_{1}$ checkpoint with concurrent wild type p53 expression. This indicates that WEE1 inhibition is a safe strategy to apply in OS patients because the radiosensitization would be cancer cell specific.

Apart from being a regulator of mitotic entry, WEE1 has been described to also affect other important cellular processes, such as regulation of mitotic spindle formation, positioning and integrity, microtubule stabilization and heat shock protein 90 (Hsp90) phosphorylation $[29,35,36]$. In this paper, we have not examined these phenomena, but it could be that the disruption of one of these processes contributes to the observed phenotype. It may be interesting to study these additional effects in the future.

Timing of combination therapy is important to obtain optimal treatment efficacy. It was reported that $\mathrm{CDC} 2$ is transiently phosphorylated to induce an arrest at the $\mathrm{G}_{2} / \mathrm{M}$ checkpoint for $12 \mathrm{~h}$ after irradiation treatment and that DNA damage could be repaired in 12-24 h after irradiation [19]. Our results support this; in irradiated cells, we observed only few remaining foci of DNA damage after $24 \mathrm{~h}$, whereas cells treated with irradiation and WEE1-inhibitor had many residual foci after $24 \mathrm{~h}$, indicating that they were unable to perform DNA repair. This suggests that DNA damaged cells are especially susceptible to WEE1-inhibitor in the first $12 \mathrm{~h}$ after induction of DNA damage. In our experimental set-up, the cells were treated with WEE1-inhibitor directly after irradiation and show a good sensitization. This suggests that cells do not have to be arrested in $\mathrm{G}_{2} / \mathrm{M}$ phase to be susceptible to WEE1 inhibition, but rather that the inability to activate (or maintain) the $G_{2}$ checkpoint in the presence of DNA damage leads to sensitization. In in vivo testing of WEE1-inhibitors, different approaches have been applied. Mir et al. [21] administered WEE1-inhibitor at 5 consecutive days around the irradiation dose, whereas Hirai et al. [18] first administered DNA damaging agents, followed by WEE1-inhibitor after a 24 hour interval. Both groups showed enhanced anti-tumor efficacy. What will be the most optimal schedule for radiotherapy combined with WEE1 inhibition in OS remains to be tested in vivo.

\section{Conclusion}

Radiotherapy is a controversial topic in the treatment of OS. Its efficacy is limited in this cancer and therefore it is not widely applied. Novel small molecules, in particular WEE1-inhibitor drugs may serve as radiosensitizers in OS. WEE1 kinase is expressed in OS and plays a critical role in DNA repair by maintaining the $G_{2}$ cell cycle arrest through inhibitory phosphorylation of CDC2. Our results show that the WEE1-inhibitor PD0166285 can abrogate the DNA damage induced $\mathrm{G}_{2} /$ $M$ cell cycle arrest in OS cells, forcing the cells into mitotic catastrophe and thus causing radiosensitization. WEE1 could therefore be a strategic, cancer cell specific drug target and its inhibition could be an effective strategy to enhance the efficacy of radiotherapy in OS.

\section{Abbreviations}

DSB: Double strand break; CDC2: Cyclin Dependent Kinase 1; Gy: Gray; YH2AX: \{Gamma\}-Histone H2AX; Hsp90: Heat shock protein 90; IR: Irradiation; IRIF: ionizing radiation induced foci; Inh: Inhibitor; MI: Mitotic index; OS: Osteosarcoma; PBS: Phosphate Buffered Saline; PD: Pro-drug; PHH3: Phospho-Histone H3; SD: Standard Deviation.

\section{Acknowledgements}

We kindly acknowledge Folkert van Kemenade for the provision of tumor samples and advice on the immunohistochemical staining. We acknowledge Wim Vos for placing his antibodies at our disposal. We thank Laurine Wedekind for her technical assistance.

Grant support: JP is supported by the Individualised Musculoskeletal Regeneration and Reconstruction Network (Danish Research Council) Aarhus, Denmark and by VONK: VUmc Onderzoek naar Kinderkanker (Stichting Research Fonds Kindergeneeskunde VUmc) Amsterdam, the Netherlands.

\section{Author details}

${ }^{1}$ Department of Orthopaedic Surgery, VU University Medical Center, PO box 7057, 1007 MB Amsterdam, the Netherlands. ${ }^{2}$ Neuro-oncology Research Group, Departments of Neurosurgery and Paediatric Oncology/Haematology, VU University Medical Center, PO box 7057, 1007 MB Amsterdam, the Netherlands. ${ }^{3}$ Molecular Neurogenetics Unit, Department of Neurology, Massachusetts General Hospital and Harvard Medical School, Boston, 13th Street, Building 149, Charlestown, MA, 02129 USA. ${ }^{4}$ Department of Medical Oncology, RNA Interference Functional Oncogenomics Laboratory (RIFOL), VU University Medical Center, Amsterdam, the Netherlands. ${ }^{5}$ Research institute MOVE/Skeletal Tissue Engineering Group Amsterdam (STEGA), PO box 7057, 1007 MB Amsterdam, the Netherlands. ' Paediatric Oncology/ Haematology, VU University Medical Center, PO box 7057, 1007 MB Amsterdam, the Netherlands.

\section{Authors' contributions}

JP performed the experiments, interpreted the experimental data, conceived and drafted the manuscript. TW and HG conceived the study and experiments. TW, HG, VB and MH helped interpret the experimental data and corrected the manuscript. BR reviewed and corrected the manuscript. GK supervised the project and critically reviewed the contents of the manuscript. All authors read and approved the final manuscript.

\section{Competing interests}

The authors declare that they have no competing interests.

Received: 6 October 2010 Accepted: 29 April 2011

Published: 29 April 2011

\section{References}

1. Delaney TF, Park L, Goldberg SI, Hug EB, Liebsch NJ, Munzenrider JE, et al: Radiotherapy for local control of osteosarcoma. Int J Radiat Oncol Biol Phys 2005, 61:492-498

2. Machak GN, Tkachev SI, Solovyev YN, Sinyukov PA, Ivanov SM, Kochergina NV, et al: Neoadjuvant chemotherapy and local radiotherapy 
for high-grade osteosarcoma of the extremities. Mayo Clin Proc 2003, 78:147-155.

3. Schwarz R, Bruland O, Cassoni A, Schomberg P, Bielack S: The role of radiotherapy in oseosarcoma. Cancer Treat Res 2010, 152:147-164.

4. Anderson PM: Effectiveness of radiotherapy for osteosarcoma that responds to chemotherapy. Mayo Clin Proc 2003, 78:145-146.

5. Anderson PM, Wiseman GA, Erlandson L, Rodriguez V, Trotz B, Dubansky SA, et al: Gemcitabine radiosensitization after high-dose samarium for osteoblastic osteosarcoma. Clin Cancer Res 2005, 11:6895-6900.

6. Bielack SS, Kempf-Bielack B, Delling G, Exner GU, Flege S, Helmke K, et al: Prognostic factors in high-grade osteosarcoma of the extremities or trunk: an analysis of 1,702 patients treated on neoadjuvant cooperative osteosarcoma study group protocols. J Clin Oncol 2002, 20:776-790.

7. Bielack SS, Carrle D, Hardes J, Schuck A, Paulussen M: Bone tumors in adolescents and young adults. Curr Treat Options Oncol 2008, 9:67-80.

8. Hundsdoerfer P, Albrecht M, Ruhl U, Fengler R, Kulozik AE, Henze G: Longterm outcome after polychemotherapy and intensive local radiation therapy of high-grade osteosarcoma. Eur J Cancer 2009, 45:2447-2451.

9. Mahajan A, Woo SY, Kornguth DG, Hughes D, Huh W, Chang EL, et al: Multimodality treatment of osteosarcoma: radiation in a high-risk cohort. Pediatr Blood Cancer 2008, 50:976-982.

10. Wagner TD, Kobayashi W, Dean S, Goldberg SI, Kirsch DG, Suit HD, et al: Combination short-course preoperative irradiation, surgical resection, and reduced-field high-dose postoperative irradiation in the treatment of tumors involving the bone. Int I Radiat Oncol Biol Phys 2009, 73:259-266.

11. Blattmann C, Oertel S, Schulz-Ertner D, Rieken S, Haufe S, Ewerbeck V, et al: Non-randomized therapy trial to determine the safety and efficacy of heavy ion radiotherapy in patients with non-resectable osteosarcoma. BMC Cancer 2010, 10:96.

12. Kamada T, Tsujii H, Tsuji H, Yanagi T, Mizoe JE, Miyamoto T, et al: Efficacy and safety of carbon ion radiotherapy in bone and soft tissue sarcomas. J Clin Oncol 2002, 20:4466-4471.

13. Anderson P, Aguilera D, Pearson M, Woo S: Outpatient chemotherapy plus radiotherapy in sarcomas: improving cancer control with radiosensitizing agents. Cancer Control 2008, 15:38-46.

14. Hughes DP: How the NOTCH Pathway Contributes to the Ability of Osteosarcoma Cells to Metastasize. Cancer Treat Res 2010, 152:479-496.

15. Anderson P, Kopp L, Anderson N, Cornelius K, Herzog C, Hughes D, et al: Novel bone cancer drugs: investigational agents and control paradigms for primary bone sarcomas (Ewing's sarcoma and osteosarcoma). Expert Opin Investig Drugs 2008, 17:1703-1715.

16. Kawabe $\mathrm{T}: \mathrm{G} 2$ checkpoint abrogators as anticancer drugs. Mol Cancer Ther 2004, 3:513-519.

17. Castedo M, Perfettini IL, Roumier T, Andreau K, Medema R, Kroemer G: Cell death by mitotic catastrophe: a molecular definition. Oncogene 2004, 23:2825-2837.

18. Hirai H, Iwasawa $Y$, Okada M, Arai T, Nishibata T, Kobayashi M, et al: Smallmolecule inhibition of Wee1 kinase by MK-1775 selectively sensitizes p53-deficient tumor cells to DNA-damaging agents. Mol Cancer Ther 2009, 8:2992-3000

19. Kim MJ, Lee JY, Lee SJ: Transient suppression of nuclear Cdc2 activity in response to ionizing radiation. Oncol Rep 2008, 19:1323-1329.

20. Reinhardt HC, Aslanian AS, Lees JA, Yaffe MB: p53-deficient cells rely on ATM- and ATR-mediated checkpoint signaling through the P38MAPK/ MK2 pathway for survival after DNA damage. Cancer Cell 2007, 11:175-189.

21. Mir SE, De Witt Hamer PC, Krawczyk PM, Balaj L, Claes A, Niers JM, et al: In Silico Analysis of Kinase Expression Identifies WEE1 as a Gatekeeper against Mitotic Catastrophe in Glioblastoma. Cancer Cell 2010, 18:244-257.

22. Jiang H, Reinhardt HC, Bartkova J, Tommiska J, Blomqvist C, Nevanlinna H, et al: The combined status of ATM and p53 link tumor development with therapeutic response. Genes Dev 2009, 23:1895-1909.

23. Raleigh JM, O'Connell MJ: The G(2) DNA damage checkpoint targets both Wee1 and Cdc25. J Cell Sci 2000, 113(Pt 10):1727-1736.

24. Gorlick R, Anderson P, Andrulis I, Arndt C, Beardsley GP, Bernstein M, et al: Biology of childhood osteogenic sarcoma and potential targets for therapeutic development: meeting summary. Clin Cancer Res 2003, 9:5442-5453.
25. Hayden JB, Hoang BH: Osteosarcoma: basic science and clinical implications. Orthop Clin North Am 2006, 37:1-7.

26. Nyberg KA, Michelson RJ, Putnam CW, Weinert TA: Toward maintaining the genome: DNA damage and replication checkpoints. Annu Rev Genet 2002, 36:617-656.

27. Stathis A, Oza A: Targeting Wee1-like protein kinase to treat cancer. Drug News Perspect 2010, 23:425-429.

28. Wang Y, Li J, Booher RN, Kraker A, Lawrence T, Leopold WR, et al: Radiosensitization of p53 mutant cells by PD0166285, a novel G(2) checkpoint abrogator. Cancer Res 2001, 61:8211-8217.

29. Hashimoto O, Shinkawa M, Torimura T, Nakamura T, Selvendiran K, Sakamoto $\mathrm{M}$, et al: Cell cycle regulation by the Wee1 inhibitor PD0166285 pyrido [2,3-d] pyimidine, in the B16 mouse melanoma cell line. BMC Cancer 2006, 6:292.

30. Syljuasen $R G$, Jensen $S$, Bartek J, Lukas J: Adaptation to the ionizing radiation-induced G2 checkpoint occurs in human cells and depends on checkpoint kinase 1 and Polo-like kinase 1 kinases. Cancer Res 2006, 66:10253-10257.

31. Wells NJ, Watanabe N, Tokusumi T, Jiang W, Verdecia MA, Hunter T: The Cterminal domain of the $\mathrm{Cdc} 2$ inhibitory kinase Myt1 interacts with $\mathrm{Cdc} 2$ complexes and is required for inhibition of G(2)/M progression. J Cell Sci 1999, 112(Pt 19):3361-3371.

32. Iurisci I, Filipski E, Reinhardt J, Bach S, Gianella-Borradori A, lacobelli S, et al: Improved tumor control through circadian clock induction by Seliciclib, a cyclin-dependent kinase inhibitor. Cancer Res 2006, 66:10720-10728.

33. Enders GH: Gauchos and ochos: a Wee1-Cdk tango regulating mitotic entry. Cell Div 2010, 5:12

34. R2. Microarray Analysis and Visualisation Platform:Edited by: Jan Koster Human Genetics Department, Academic Medical Center, Amsterdam, the Netherlands; 2010:[http://r2.amc.nl], 3-9-2010. Ref Type: Electronic Citation.

35. Mollapour M, Tsutsumi S, Donnelly AC, Beebe K, Tokita MJ, Lee MJ, et al: Swe1Wee1-dependent tyrosine phosphorylation of $\mathrm{Hsp90}$ regulates distinct facets of chaperone function. Mol Cell 2010, 37:333-343.

36. Garcia K, Stumpff J, Duncan T, Su T: Tyrosines in the kinesin-5 head domain are necessary for phosphorylation by Wee1 and for mitotic spindle integrity. Curr Biol 2009, 19:1670-1676.

\section{Pre-publication history}

The pre-publication history for this paper can be accessed here: http://www.biomedcentral.com/1471-2407/11/156/prepub

\section{doi:10.1186/1471-2407-11-156}

Cite this article as: PosthumaDeBoer et al:: WEE1 inhibition sensitizes osteosarcoma to radiotherapy. BMC Cancer 2011 11:156.

\section{Submit your next manuscript to BioMed Central and take full advantage of:}

- Convenient online submission

- Thorough peer review

- No space constraints or color figure charges

- Immediate publication on acceptance

- Inclusion in PubMed, CAS, Scopus and Google Scholar

- Research which is freely available for redistribution 